\title{
GAD1 expression and its methylation as indicators of malignant behavior in thymic epithelial tumors
}

\author{
SHIHO SOEJIMA ${ }^{1}$, KAZUYA KONDO ${ }^{1}$, MITSUHIRO TSUBOI ${ }^{2}$, KYOKA MUGURUMA ${ }^{1}$, BILGUUN TEGSHEE ${ }^{1}$, \\ YUKIKIYO KAWAKAMI $^{2}$, KOICHIRO KAJIURA ${ }^{2}$, NAOYA KAWAKITA ${ }^{2}$, HIROAKI TOBA ${ }^{2}$, \\ MITSUTERU YOSHIDA ${ }^{2}$, HIROMITSU TAKIZAWA ${ }^{2}$ and AKIRA TANGOKU ${ }^{2}$ \\ ${ }^{1}$ Department of Oncological Medical Services, Graduate School of Biomedical Sciences, Tokushima University, \\ Tokushima 770-8509; ${ }^{2}$ Department of Thoracic, Endocrine Surgery and Oncology, \\ Graduate School of Biomedical Sciences, Tokushima University, Tokushima 770-8503, Japan
}

Received October 30, 2020; Accepted March 23, 2021

DOI: $10.3892 / \mathrm{ol} .2021 .12744$

\begin{abstract}
Thymic epithelial tumors (TETs) comprise thymomas and thymic carcinoma (TC). TC has more aggressive features and a poorer prognosis than thymomas. Genetic and epigenetic alterations in thymomas and TC have been investigated in an attempt to identify novel target molecules for TC. In the present study, genome-wide screening was performed on aberrantly methylated $\mathrm{CpG}$ islands in thymomas and $\mathrm{TC}$, and the glutamate decarboxylase 1 gene (GADI) was identified as the 4th significantly hypermethylated $\mathrm{CpG}$ island in TC compared with thymomas. GADl catalyzes the production of $\gamma$-aminobutyric acid from L-glutamic acid. $G A D 1$ expression is abundant in the brain but rare in other tissues, including the thymus. A total of 73 thymomas and 17 TC tissues were obtained from 90 patients who underwent surgery or biopsy at Tokushima University Hospital between 1990 and 2017. DNA methylation was examined by bisulfite pyrosequencing, and the mRNA and protein expression levels of $G A D 1$ were analyzed using reverse transcription-quantitative PCR and immunohistochemistry, respectively. The DNA methylation levels of GADl were significantly higher in TC
\end{abstract}

Correspondence to: Professor Kazuya Kondo, Department of Oncological Medical Services, Graduate School of Biomedical Sciences, Tokushima University, 3-18-15 Kuramoto-cho, Tokushima 770-8509, Japan

E-mail: kzykondo@tokushima-u.ac.jp

Abbreviations: TET, thymic epithelial tumor; TC, thymic carcinoma; CGI, CpG islands; GAD1, glutamate decarboxylase 1; GABA, $\gamma$-aminobutyric acid; CTCF, CCCTC-binding factor; IHC, immunohistochemistry; IQR, interquartile range; ROC, receiver operating characteristic; HR, hazard ratio; RFS, relapse-free survival; PRC2, polycomb repressive complex 2; AUC, area under the ROC curve; H3K27me3, histone H3 lysine 27 trimethylation; MMP-7, matrix metalloproteinase-7

Key words: TC, thymoma, GAD1, DNA methylation, paradoxical expression, poor prognosis tissues than in the normal thymus and thymoma tissues, and GADl methylation exhibited high sensitivity and specificity for discriminating between TC and thymoma. The mRNA and protein expression levels of $G A D l$ were significantly higher in TC tissues than in thymomas. Patients with TET with high GADI DNA hypermethylation and high mRNA and protein expression levels had significantly shorter relapse-free survival rates than those with low levels. In conclusion, significantly more epigenetic alterations were observed in TC tissues compared with in thymomas, which may contribute to the clinical features and prognosis of patients.

\section{Introduction}

Thymomas and thymic carcinoma (TC) are rare primary tumors of the anterior mediastinum. Although they are derived from the thymic epithelium, their biological characteristics markedly differ (1). Thymomas are low-grade malignant tumors with a variable population of immature, but non-neoplastic T cells associated with myasthenia gravis and other autoimmune diseases. In most cases, thymomas are successfully treated with surgery and/or adjuvant radiotherapy. Outcomes depend on the tumor subtype, and patients sometimes require supplementary chemotherapy. When recurrence and/or residual tumors are present, the clinical course is indolent. In contrast, TC is a malignant tumor without immature T-cell infiltration and autoimmune disease (2). It has more aggressive features and a poorer prognosis (5-year overall survival rate: Approximately 50\%) $(3,4)$. The outcomes of metastatic or inoperable refractory/recurrent TC are extremely poor due to the lack of a standard chemotherapy regimen $(5,6)$. The rarity of this tumor makes clinical trials difficult, and, thus, the development of new drugs is slow. Previous studies examined the effects of targeted therapies and immunomodulatory agents for thymic epithelial tumors (TET) (7). The findings obtained revealed that only sunitinib (an oral tyrosine kinase inhibitor of VEGFR, KIT, and PDGFR) and pembrolizumab (an immune checkpoint inhibitor) were active against TC (response rates of 26 and $22.5 \%$, respectively) $(8,9)$. To identify novel target molecules for TC therapy, a more detailed understanding of the aberrant pathways involved in TC using new molecular methods is needed. 
Genetic alterations in thymomas and TC have been comprehensively examined using next-generation sequencing, and the findings obtained showed that the frequency of genetic alterations was significantly higher in TC than in thymomas $(10,11)$. Genetic mutations have been detected in TP53, TET2, CYLD, BRD7, SETD2, and CDKN2A in TC (10-13). Petrini et al (14) demonstrated that GTF2IL424H mutations were the most common in type $\mathrm{A}$ and $\mathrm{AB}$ thymomas. Limited information is currently available on epigenetic alterations in TET (15-18). We previously reported that the aberrant methylation of 4 cancer-related genes (DAPK, p16, MGMT, and HPP1) was significantly more frequent in TC than in thymomas $(15,16)$. We also performed genome-wide screening on aberrantly methylated $\mathrm{CpG}$ islands (CGI) in TET and identified 92 that were significantly hypermethylated in TC (17). We selected 4 genes (GNG4, GHSR, HOXD9, and SALL3) and demonstrated that the promoter methylation of cancer-related genes was significantly higher in TC than in thymomas (18). These epigenetic alterations were of high diagnostic value for TC and may be used in targeted therapy for TC.

Genome-wide screening on CGI identified the glutamate decarboxylase 1 gene $(G A D I)$ as the 4th significantly hypermethylated CGI in TC in relation to B3 thymomas. GAD1 catalyzes the production of $\gamma$-aminobutyric acid (GABA) from L-glutamic acid, the principal inhibitory neurotransmitter $(19,20)$. The overexpression of $G A D l$ has been reported in various neoplastic tissues, such as oral, nasopharyngeal, colorectal, liver, gastric, and lung cancers (21-26). Yan et al showed that the GADl promoter was hypermethylated in both colorectal and liver cancers, leading to the production of high levels of $G A D 1$ (21). GADl is a target gene that is silenced by histone $\mathrm{H} 3$ lysine 27 trimethylation (H3K27me3). The key locus responsible for the reactivation of $G A D l$ was mapped to a DNA methylation-sensitive CCCTC-binding factor (CTCF)-binding site (CTCF-3) within the third intron of GADl (Fig. 1A).

The primary role of CTCF is in the regulation of the $3 \mathrm{D}$ structure of chromatin and also in the regulation of genes (27). CTCF binds to the consensus sequence CCGCGNGGNGGCAG (28). The binding of CTCF was shown to be disrupted by $\mathrm{CpG}$ methylation of the DNA to which it binds (4).

In the present study, we investigated the DNA methylation and mRNA and protein expression levels of GADI in TET. We also examined the prognostic significance of $G A D l$ expression in TET.

\section{Materials and methods}

Patients and tissue samples. TET samples were obtained from 90 patients with histologically proven TET who underwent surgery or biopsy at Tokushima University Hospital (Tokushima, Japan) between 1990 and 2017. Fifty-four tumors and 21 paired thymic tissues were snap-frozen and stored at $-80^{\circ} \mathrm{C}$. Thymic tissues located away from tumors were obtained during surgery. DNA was extracted from 47 tumor samples and 21 thymic samples and used in a DNA methylation analysis. RNA was extracted from 37 tumor samples and used for RT-PCR. DNA and RNA were extracted from 30 tumor samples. The formalin-fixed and paraffin-embedded materials of 81 samples were used for immunohistochemistry (IHC) (Table SI).
All TET were classified according to the World Health Organization (WHO) histological classification system (29). The clinical stage of each TET was evaluated according to the criteria of the Masaoka-Koga staging system (30). The clinical and pathological characteristics (sex, age, WHO histological classification, Masaoka-Koga stage classification, and myasthenia gravis) of patients subjected to pyrosequencing, RT-PCR, and IHC analyses are shown in Tables I and SI. This study included a case which was diagnosed with thymic carcinoma and type B2 thymoma. Several papers reported tumors combined thymic carcinoma and thymoma $(31,32)$. As main area of this tumor showed thymic carcinoma histologically and the area extracted DNA showed thymic carcinoma histologically, we included it as 'thymic carcinoma' group.

The present study was performed in accordance with the principles outlined in the Declaration of Helsinki. Following the approval of all aspects of these studies by the local Ethics Committee (Tokushima University Hospital, approval no. 2205-4), formal written consent was obtained from all patients.

DNA and RNA preparation and bisulfite conversion of genomic DNA. Tumors were snap-frozen and stored at $-80^{\circ} \mathrm{C}$ until DNA and RNA analyses. DNA and RNA were extracted using standard methods. The bisulfite conversion of DNA was conducted using the EpiTect Bisulfite Kit (Qiagen $\mathrm{GmbH}$ ) according to the manufacturer's instructions.

Global methylation analysis. We previously screened 7 TC and 8 B3 thymoma samples obtained from freshly frozen specimens with Illumina HumanMethylation450 K BeadChip to identify differentially methylated CGI in a genome-wide manner $(17,18)$. The hypermethylation of $92 \mathrm{CGI}$ in TC samples differed from that in B3 thymoma samples [FDR $<0.05$ and $\beta$-difference (TC-B3 thymoma) $>0.3$ ] (18). CGI within the $G A D 1$ gene were the 4th significantly hypermethylated CGI in $\mathrm{TC}$ in relation to $\mathrm{B} 3$ thymomas (18).

A schematic diagram of the GADl structure is shown in Fig. 1A. GAD1 mRNA had 16 exons and four CGI were located in the promoter and first three exons of GADI. Four CTCF-binding sites of GADI and the sequence of the four putative CTCF-binding sites at the human GAD1 locus were shown in Fig. 1A. The CpG dinucleotide in the CTCF-binding site is underlined. Yan et al reported that since the CTCF-3 site had four CpG sites, the methylation of these sites in CTCF-3 inhibited CTCF binding and promoted the $G A D 1$ reaction (21). The CTCF-3 site was sensitive to DNA methylation, which may have contributed to the overexpression of GADl. Fig. 1B shows the results of the array-based methylation status of each CpG site within the four CGI of GADI. The CGI-3 (from cg07420274 to cg14005211) and CGI-4 (from cg14486905 to cg08863440) regions had significantly higher methylation levels in TC samples $(\mathrm{P}<0.05)$. The $\mathrm{CpG}$ site cg15126544 in the CTCF-3 site of GADI is shown as a dotted box. We also assessed the methylation status of the $4 \mathrm{CpG}$ sites within CTCF-3, including cg15126544 of GADI.

Bisulfite pyrosequencing. Bisulfite-treated genomic DNA was amplified using a set of primers designed with PyroMark Assay Design Software (version 2.0.01.15; Qiagen; Table SII). The target region of the sequence was 10 nucleotides (nt) 
before and $26 \mathrm{nt}$ after $\mathrm{cg} 15126544$ (CpG site). There were four $\mathrm{CpG}$ sites in this region of the CTCF-3 site. PCR product pyrosequencing and methylation quantification were performed using the PyroMark 24 Pyrosequencing System (version 2.0.6; Qiagen) with sequencing primers according to the manufacturer's instructions.

Reverse transcription-quantitative $P C R$ (RT-qPCR). Complementary DNA was generated from isolated total RNA using the iScript Reverse Transcription Supermix for RT-PCR (Bio-Rad). qPCR was conducted using the KAPA PROBE FAST qPCR Kit (Kapa Biosystems) and GAD1 TaqMan Gene Expression Assay (Thermo Fisher Scientific, Inc.) according to the manufacturers' instructions. Primers used for qPCR on GADI and GAPDH are listed in Table SII. GAPDH mRNA levels were employed as internal controls for normalization. The relative expression of GADl mRNA was calculated using Human Thymus Total RNA (Takara) as a normal thymus control.

IHC staining. Three-micrometer-thick paraffin-embedded sections were subjected to IHC staining using the Envision system (ChemMate Envision kit; Dako) according to the manufacturer's instructions. A mouse monoclonal anti-GAD67 antibody (Sigma-Aldrich; Merck KGaA; G5419), diluted 1:500 with antibody diluents (Dako), was used as the primary antibody. Antigen retrieval was performed by heating dewaxed and dehydrated sections in Dako Real Target Retrieval Solution, pH 9 (Dako) using a 2100 retriever (Aptum Biologics, Ltd.). The proportion and intensity of the GAD1 stain in TET samples were scored. We defined the stain score as the sum of the proportion and intensity scores. A stain score of $\geq 4$ indicated the overexpression of the GAD1 protein (Table SIII). IHC data scoring was performed independently by two different researchers (SS and KKo).

Statistical analysis. The Shapiro-Wilk test was used to evaluate whether numerical datasets were normally distributed. Parametric tests (a paired t-test, the Student's t-test, or Welch's t-test) were used when numerical datasets were normally distributed. On the other hand, non-parametric tests (the Wilcoxon signed-rank test or Mann-Whitney test) were used when numerical datasets were not normally distributed. Continuous data were expressed as medians and ranges or interquartile ranges (IQR, 25th to 75th percentile). Data were analyzed using Kruskal Wallis test and Steel-Dwass test for multiple comparisons in histology and stage. The unpaired t-test was used for age distribution, Fisher's exact test for sex, histology, and stage distributions, and the chi-squared test for the distribution of myasthenia gravis. The area under the receiver operating characteristic (ROC) curve [AUC; ranging between 0.5 (chance) and 1.0 (perfect discrimination or accuracy)] was measured to characterize the accuracy of the DNA methylation signature to discriminate TC from thymomas. Correlation analysis was performed using Spearman's rank correlation. Relapse-free survival (RFS) was defined as 'the time from surgical resection to relapse of disease'. Univariate and multivariate survival analyses were performed using the likelihood ratio test of the stratified Cox's proportional hazard regression analysis. Survival curves were estimated using the Kaplan-Meier method and compared with the Log-rank test and the Gehan-Breslow-Wilcoxon test. All statistical analyses were performed using a commercial software program (GraphPad Prism, version 5.00; GraphPad Software and SPSS, version 24.0; IBM Corp.). A P-value $<0.05$ was considered to be significant.

\section{Results}

CGI methylation status of GAD1 genes in TET and a paired normal thymus in pyrosequencing. Fig. 1C (left side) shows the relationship of the DNA methylation rate of the four $\mathrm{CpG}$ sites of CTCF-3 in the GAD1 gene between thymomas and the normal thymus. No significant difference was observed in the DNA methylation rate between thymomas and the normal thymus (the paired t-test, $\mathrm{P}=0.917$ ). Fig. $1 \mathrm{C}$ (right side) shows the relationship of the DNA methylation rate of the GADI gene between TC and the normal thymus. The DNA methylation rate was significantly higher in $\mathrm{TC}$ than in the normal thymus (the Wilcoxon signed-rank test, $\mathrm{P}=0.003$ ).

CGI methylation status of the GADI gene in the pyrosequencing of TET according to the WHO histological classification. Fig. 1D shows the median DNA methylation rate of the GADI gene in TET according to the WHO histological classification. Median DNA methylation rates in A+AB+B1, B2, B3, and TC were 4.0 (range, 2.8-17.5, IQR, 3.0-5.9), 3.5 (range, 2.5-5.5, IQR, 3.1-4.7), 4.5 (range, 3.0-28.0, IQR, 3.4-16.4), and 32.9 (range, 12.3-75.3, IQR, 19.5-51.7), respectively. Fig. 1E shows that the median DNA methylation rate was significantly higher in TC than in thymomas [32.9 (range, 12.3-75.3, IQR, 19.5-51.7] versus (vs.) 4.0 (range, 2.5-28.0,IQR 3.3-5.3)) (the Mann-Whitney $\mathrm{U}$ test, $\mathrm{P}<0.001)$. No significant differences were observed in the median DNA methylation rate according to the WHO histological classification in thymomas $(\mathrm{A}+\mathrm{AB}+\mathrm{B} 1$ vs. $\mathrm{B} 2, \mathrm{~B} 2$ vs. $\mathrm{B}$, and $\mathrm{A}+\mathrm{AB}+\mathrm{B} 1$ vs. $\mathrm{B} 3)$. The median DNA methylation rate of TC was significantly higher than in each thymoma group $(\mathrm{A}+\mathrm{AB}+\mathrm{B} 1, \mathrm{~B} 2$ and $\mathrm{B} 3)(\mathrm{P}<0.01)$. We examined the accuracy of the methylation signature of $G A D l$ for the detection of TC using the ROC analysis. We used the area under the ROC curve (AUC) as the criterion of accuracy. AUC may range, in value from 0.5 (chance) to 1.0 (perfect discrimination or accuracy). Fig. 1F shows ROC curves for the accuracy of the GADl methylation signature to differentiate TC from all tumors. The results obtained revealed high sensitivity and specificity for discriminating between $\mathrm{TC}$ and thymomas ( $\mathrm{AUC}=0.9758$ ).

mRNA expression of GADI in TET. Relative mRNA expression levels were normalized to GAPDH mRNA levels and expressed as the mean of experiments performed in triplicate. Median mRNA expression levels in A+AB+B1, B2, B3, and TC were 0.20 (range, 0.02-4.40, IQR, 0.08-1.26), 0.40 (range, 0.02-3.85, IQR, 0.07-0.87), 0.40 (range, 0.01-1.70, IQR, $0.08-0.78$ ), and 1.85 (range, $0.25-29.76$, IQR, 1.21-6.65), respectively (Fig. 2A). The RT-qPCR analysis showed that median GAD1 mRNA expression levels were 1.85 (range, 0.25-29.76, IQR, 1.21-6.65) in TC samples and 0.38 (range, 0.01-4.40, IQR, 0.08-0.86) in thymoma samples. GADl mRNA expression levels were significantly higher in TC than in thymomas (the Mann-Whitney U test, $\mathrm{P}=0.0004$ ) (Fig. 2B). A positive association was observed between mRNA expression levels 

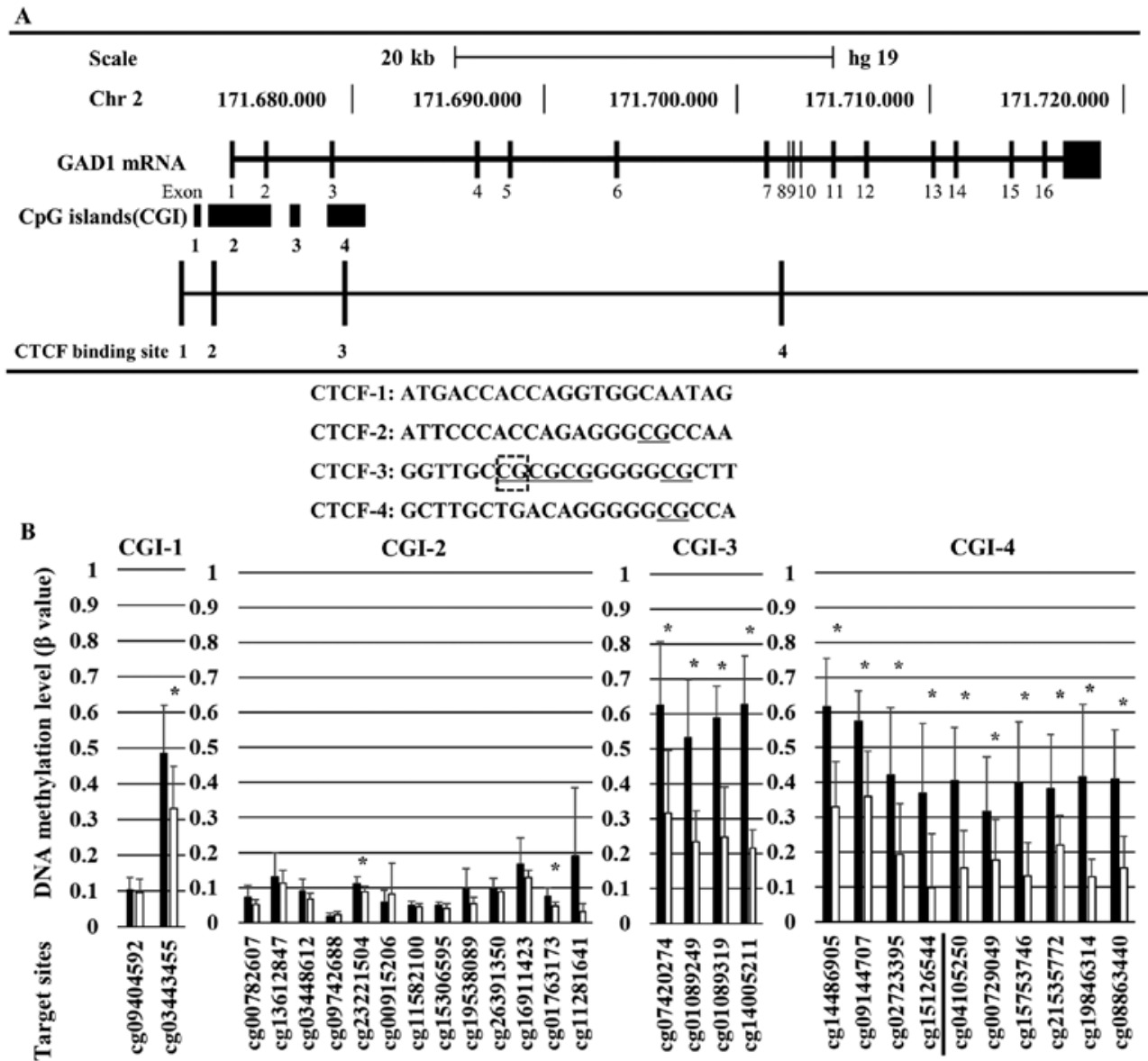

C
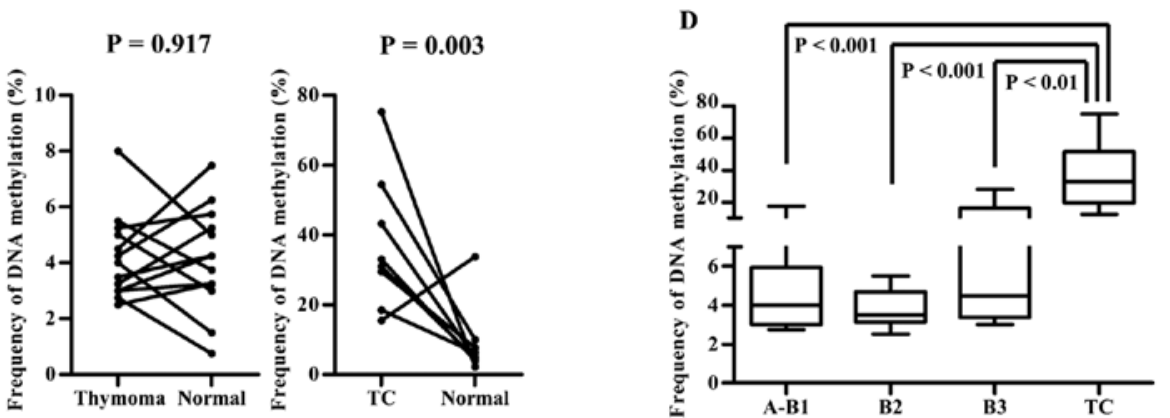

E

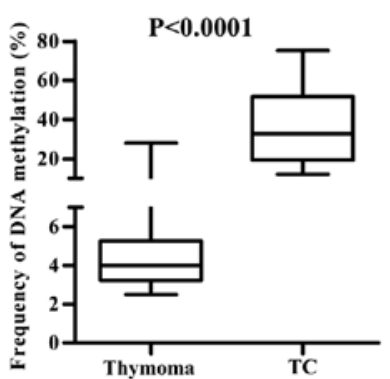

$\mathbf{F}$

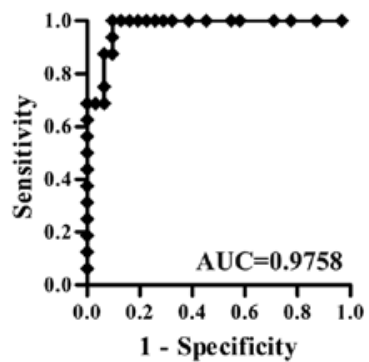

Figure 1. (A) Schematic diagram of the GAD1 structure. The mRNA of GAD1 has 16 exons. Four CGI (black boxes) are located in the promoter and the first three exons of GAD1. Four CTCF-binding sites of GAD1 are shown as vertical lines. The sequences of the four putative CTCF-binding sites at the human GAD1 locus are shown. CpG dinucleotides in the CTCF-binding site are underlined. The CpG site cg15126544 in the CTCF-3 site of GAD1 is shown as a dotted box. (B) DNA methylation levels. The vertical scale indicates average $\beta$-values of the DNA methylation level of each CpG site between TC (black bar) and B3 thymomas (white bar). The target region for the pyrosequencing analysis began 10 nucleotides before and 26 nucleotides after cg15126544 (underlined). "P<0.05 TC vs. thymoma. (C) DNA methylation rate of the GADl gene in thymomas and paired normal thymic tissues, and in TC and paired normal thymic tissues. Average DNA methylation values are shown as percentages from the quantitative pyrosequencing of 13 thymomas and paired thymic tissues, and 8 TC and paired thymic tissues. (D) DNA methylation rate of the $G A D 1$ gene in thymic epithelial tumors according to the World Health Organization histological classification (A+AB+B1, B2, B3 and TC). The upper and lower ends of the whiskers, the upper and lower edges of the boxes, and the horizontal lines across each box represent the upper and lower extremes, the upper (75th) and lower (25th) quartiles, and the medians, respectively. Data were analyzed using Kruskal Wallis test ( $\mathrm{P}<0.0001)$ and Steel-Dwass test. (E) Median DNA methylation rate between TC and thymomas (A+AB+B1+B2+B3) was 32.88 (range, 12.25-75.25; IQR, 19.50-51.69) vs. 4.0 (range, 2.5-28.0; IQR, 3.25-5.25) respectively. (F) Receiver operating characteristic curve of the accuracy of the methylation signature for detecting TC among all tumors using GADl methylation. CTCF, CCCTC-binding factor; TC, thymic carcinoma; GAD1, glutamate decarboxylase 1; IQR, interquartile range; AUC, area under the curve. 


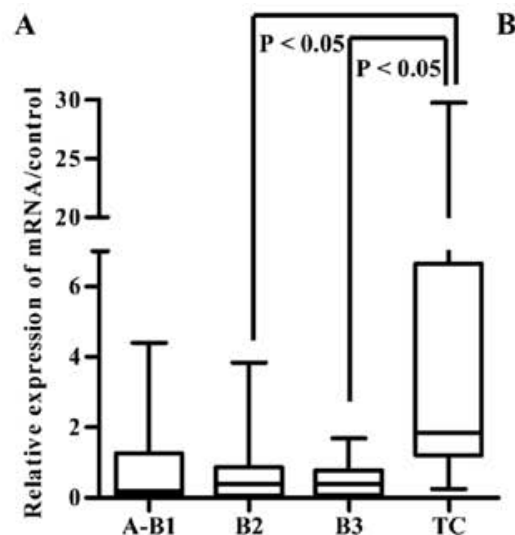

B
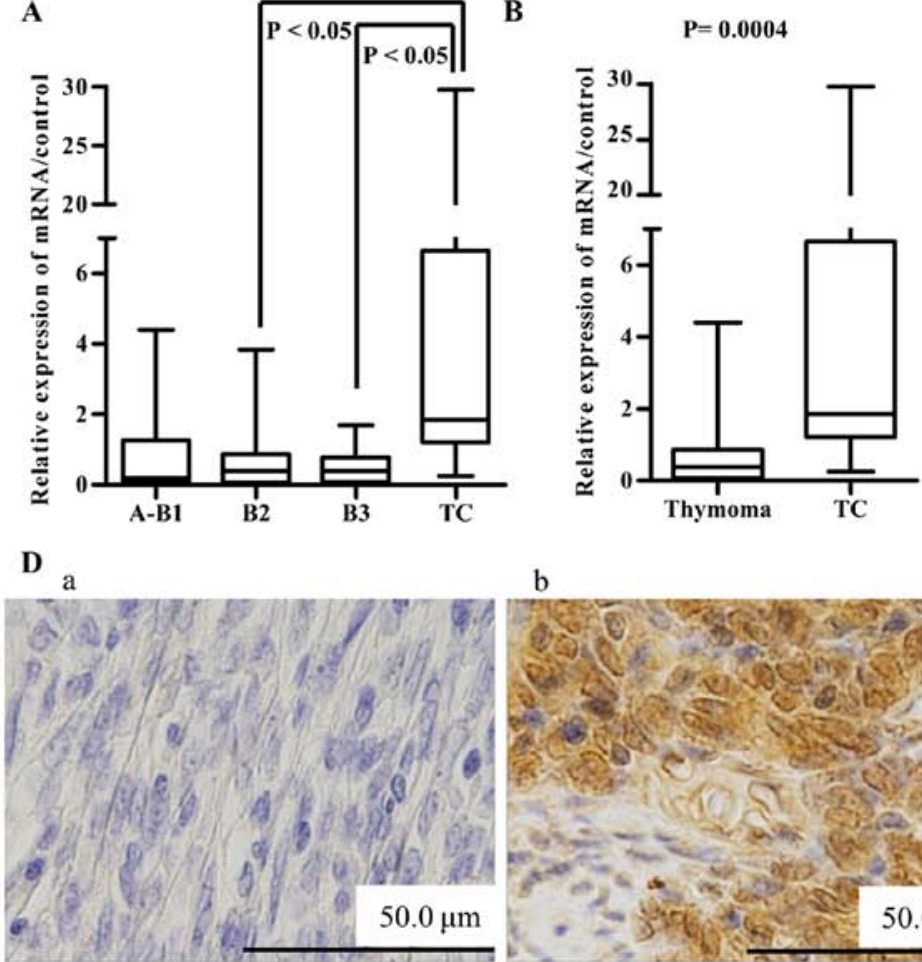

d

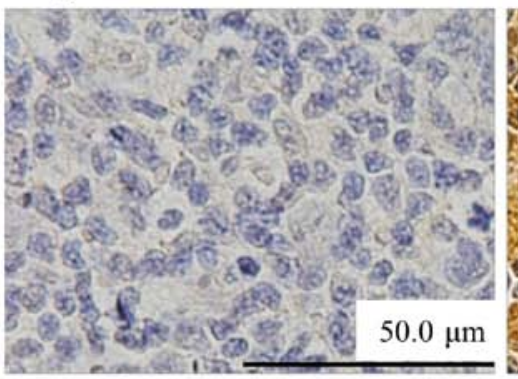

b

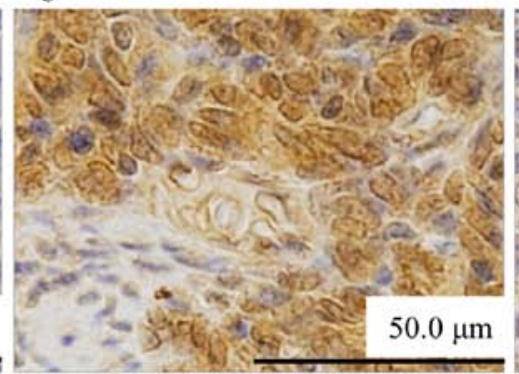

e

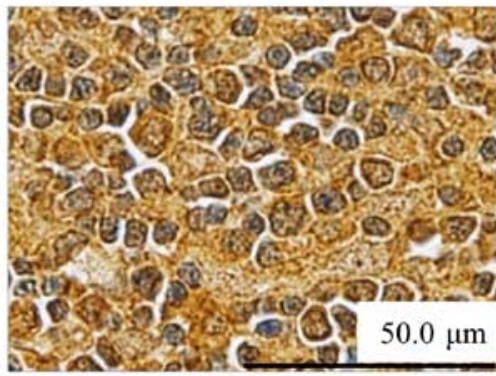

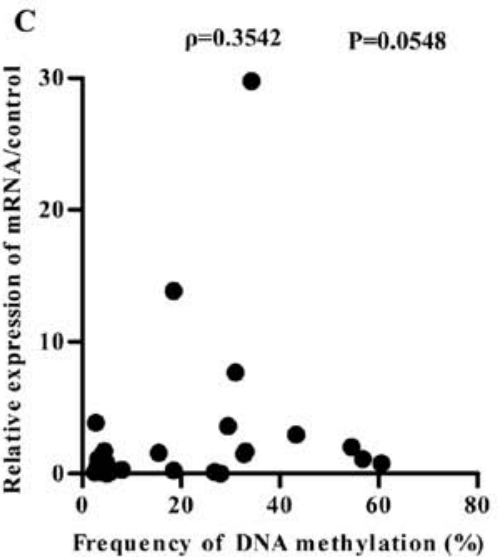

c

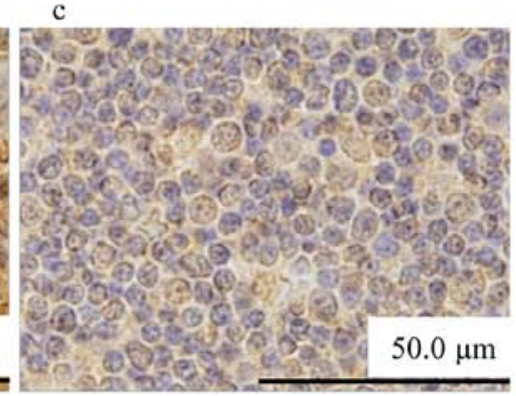

f

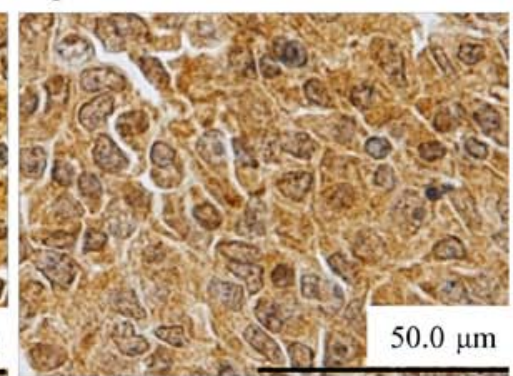

$\mathbf{E}$

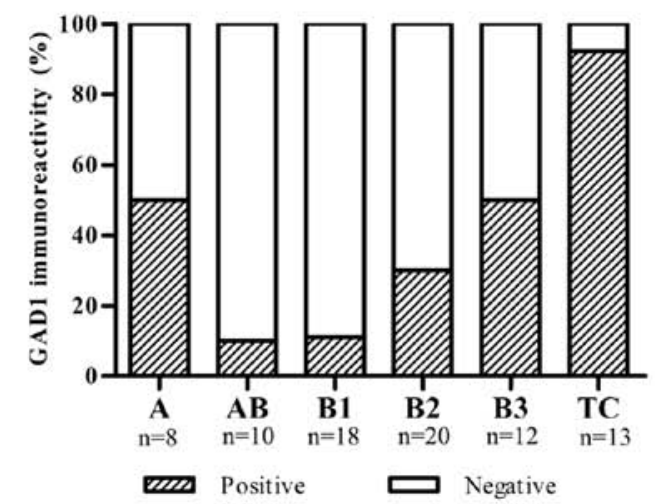

Figure 2. (A) GAD1 mRNA expression in TET according to the WHO histological classification (A+AB+B1, B2, B3 and TC). The upper and lower ends of the whiskers, the upper and lower edges of the boxes, and the horizontal lines across each box represent the upper and lower extremes, the upper (75th) and lower (25th) quartiles, and the medians, respectively. Data were analyzed via Kruskal Wallis test ( $\mathrm{P}=0.0058)$ and the Steel-Dwass test. (B) GAD1 mRNA expression between $\mathrm{TC}$ and thymomas $(\mathrm{A}+\mathrm{AB}+\mathrm{B} 1+\mathrm{B} 2+\mathrm{B} 3$ ) was 1.85 (range, $0.25-29.76, \mathrm{IQR}, 1.21-6.65$ ) vs. 0.38 (range 0.01-4.40, IQR, 0.08-0.86), respectively. (C) Correlation between DNA methylation levels of four CpG sites within the CTCF-3 of GAD1 and GAD1 mRNA expression in 18 thymomas and 12 TC tissues. Data were analyzed via Spearman's rank correlation. (D) Representative images of the immunohistochemically detected GAD1 protein in tumors. (a) Type A thymoma: the cytoplasm of tumor cells was not stained; (b) type AB thymoma: the cytoplasm of tumor cells was strongly stained; (c) type B1 thymoma: the cytoplasm of tumor cells was weakly stained and lymphocytes were not stained; (d) type B2 thymoma: the cytoplasm of tumor cells was not stained; (e) type B3 thymoma: the cytoplasm of tumor cells was strongly stained and lymphocytes were not stained; and (f) TC: the cytoplasm of tumor cells of thymic carcinoma was strongly stained. Scale bar, $50 \mu \mathrm{m}$. (E) GAD1 protein expression in TET according to the WHO histological classification. TC, thymic carcinoma; GAD1, glutamate decarboxylase 1; IQR, interquartile range; TET, thymic epithelial tumor; WHO, World Health Organization.

and methylation levels at the $4 \mathrm{CpG}$ sites (Spearman's rank correlation coefficient, $\mathrm{Q}=0.3542, \mathrm{P}=0.0548$ ) (Fig. 2C).
Protein expression of GAD1 using IHC. To assess GAD1 protein expression levels in TET, IHC was performed on 81 
A

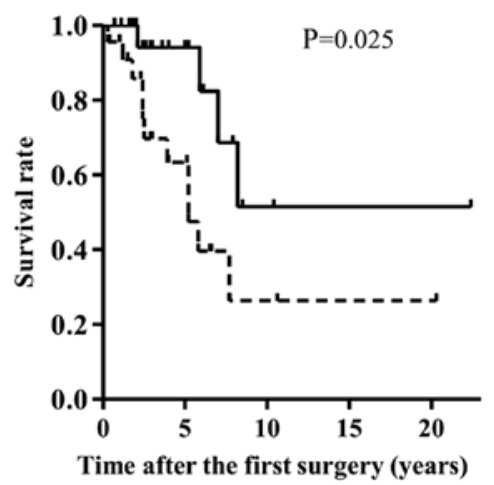

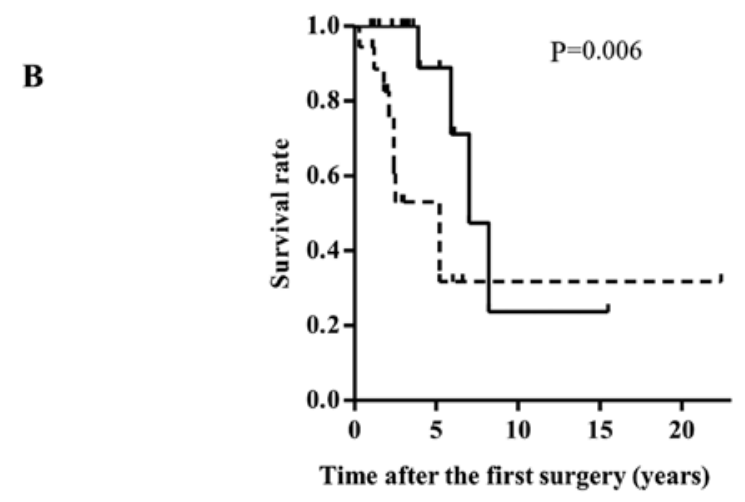

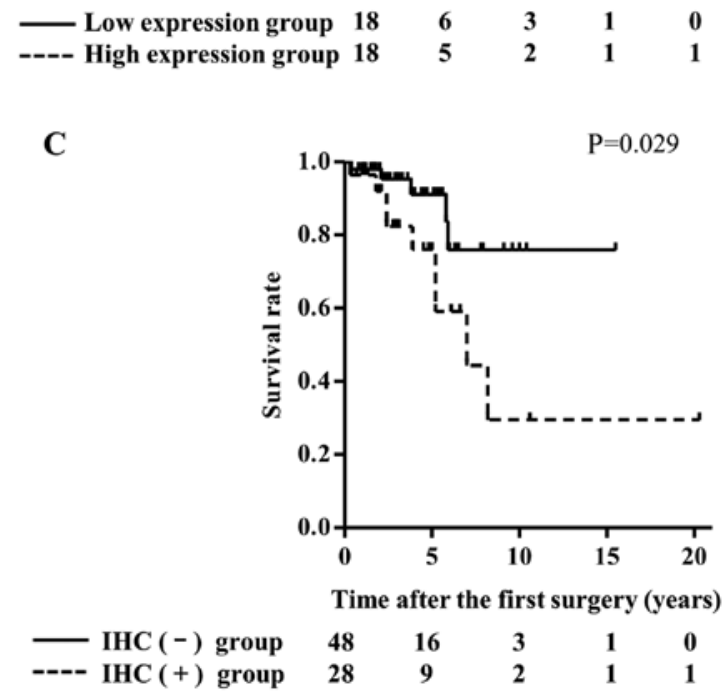

Figure 3. (A) Relapse-free survival curves of patients with TET with higher and lower levels of DNA methylation in GAD1. The median value (5.375) of the frequency of the DNA methylation of GADl was used to divide patients into hypermethylated and hypomethylated groups. P-value was calculated using the log-rank test. (B) Relapse-free survival curves of patients with TET with higher and lower levels of GAD1 mRNA expression. The median value (0.69) of GAD1 mRNA expression was used to divide patients into high and low expression groups. P-value was calculated using the Gehan-Breslow-Wilcoxon test. (C) Relapse-free survival curves of patients with TET with higher and lower levels of GAD1 protein expression. The immunoreactivity (staining score) of $G A D 1$ was used to divide patients into $\mathrm{IHC}(+)$ (staining score $\geq 4$ ) and IHC(-) (staining score $<4$ ) groups. P-value was calculated using the log-rank test. GAD1, glutamate decarboxylase 1; IHC, immunohistochemistry; TET, thymic epithelial tumor.

TET, including 68 thymomas and 13 TC. Patient characteristics are shown in Table I. Cytoplasmic staining of GAD1 was observed in the tumor cells of TC (Fig. 2D-f), whereas almost

no staining was noted in thymoma cells (Fig. 2D-a and d). Some cells of type A and B3 thymoma were strongly stained (Fig. 2D-b and c). Fig. 2D-b showed weakly stained tumor cells in type B1 thymomas. Fig. 2E showed the immunoreactivity of GAD1 in the WHO histological classification. Reactivity increased in order from type AB thymomas to TC. A significant difference was observed in the expression of GAD1 between TC and thymomas ( 92.31 vs. $27.94 \%, \mathrm{P}<0.001$ ). Among the various clinicopathological factors examined, the Masaoka-Koga staging system, WHO histological classification, mRNA expression, and DNA methylation correlated with GAD1 immunoreactivity (Table II).

Univariate and multivariate survival analyses using the stratified Cox's proportional hazard regression analysis. The univariate Cox's regression analysis confirmed that the WHO histological classification (Hazard ratio (HR); 3.974, 95\% confidence interval (95\% CI); 1.990-7.938), Masaoka-Koga staging system (HR; 5.532, 95\% CI; 1.941-15.771), and GAD1 DNA methylation (HR; 3.424, 95\% CI; 1.082-10.835) correlated with a worse prognosis for RFS (Table III). The multivariate Cox's regression analysis revealed that the WHO histological classification (HR; 7.517, 95\% CI; 2.156-26.202) and Masaoka-Koga staging system (HR; 5.727, 95\% CI; 1.689-19.423) were independent prognostic factors for RFS (Table III). GADI immunoreactivity was associated with RFS in the univariate Cox's regression analysis; (HR; 2.800, 95\% CI; 0.996-7.870, $\mathrm{P}=0.051$ ) and multivariate Cox's regression analysis; (HR; 0.213, 95\% CI; 0.034-1.321, $\mathrm{P}=0.097)$.

RFS curve of TET according to DNA methylation, mRNA, and protein overexpression levels. In all TET cases $(\mathrm{n}=90)$, the median follow-up time was 3.84 years $(0.36-22.41$ years). Two patients died from their tumors, five from another disease, and two had no known cause of death. Seventeen patients had recurrence: pleural dissemination in 10, lung metastasis in 4 , lymph node metastasis in 2, and multiple organ metastasis in 1 . In thymoma cases $(n=73)$, the median follow-up time was 3.86 years (0.75-22.41 years). One patient died due to their tumor, five from another disease, and two had no known cause of death. Nine patients had recurrence: Pleural dissemination in 7 and lung metastasis in 2.

Patients with TET were divided into 2 groups according to the median value of the frequency of DNA methylation. Twenty-three patients had a median frequency of DNA methylation of the GADl gene $>5.375$ (higher DNA methylation level), while that for the remaining 23 patients was $<5.375$ (lower DNA methylation level). Patients with TET were divided into 2 groups according to the median value of the relative expression of mRNA. Eighteen patients had a median value for the relative expression of mRNA $>0.69$ (higher mRNA expression), while that for the remaining 18 patients was $<0.69$ (lower mRNA expression).

Kaplan-Meier curves of estimated RFS were generated according to the GAD1 DNA methylation, mRNA, and protein expression status of TET. Patients with high GAD1 DNA methylation levels had significantly shorter RFS $(\mathrm{P}=0.029$, the Log-rank test) than those with low GAD1 DNA methylation levels (Fig. 3A). Patients with high GAD1 
Table I. Clinicopathological characteristics of 90 patients with thymic epithelial tumors used for IHC analysis ( $\mathrm{n}=81$ ), pyrosequencing analysis $(\mathrm{n}=47)$ and RT-qPCR analysis $(\mathrm{n}=37)$.

\begin{tabular}{|c|c|c|c|c|}
\hline Characteristics & Total & IHC analysis & $\begin{array}{l}\text { Pyrosequencing } \\
\text { analysis }\end{array}$ & $\begin{array}{l}\text { RT-qPCR } \\
\text { analysis }\end{array}$ \\
\hline \multicolumn{5}{|l|}{ Sex, n (\%) } \\
\hline Male & $31(34.4)$ & $27(33.3)$ & $19(40.4)$ & $14(37.8)$ \\
\hline Female & $59(65.6)$ & $54(66.7)$ & $28(59.6)$ & $23(62.2)$ \\
\hline Age, mean \pm SD (years) & $59.7 \pm 13.0$ & $59.2 \pm 13.0$ & $59.5 \pm 12.3$ & $60.9 \pm 12.3$ \\
\hline \multicolumn{5}{|l|}{ Myasthenia gravis, n (\%) } \\
\hline With & $19(21.1)$ & $17(21.0)$ & $10(21.3)$ & $9(24.3)$ \\
\hline Without & $71(7.6)$ & $64(79.0)$ & $37(78.7)$ & $28(75.7)$ \\
\hline \multicolumn{5}{|c|}{$\begin{array}{l}\text { World Health Organization histological } \\
\text { classification, n (\%) }\end{array}$} \\
\hline Thymoma & $73(81.1)$ & $68(84.0)$ & $31(66.0)$ & $25(67.6)$ \\
\hline A & $9(10.0)$ & $8(9.9)$ & $5(10.6)$ & $2(5.4)$ \\
\hline $\mathrm{AB}$ & $11(12.2)$ & $10(12.3)$ & $2(4.3)$ & $3(8.1)$ \\
\hline B1 & $19(21.1)$ & $18(22.2)$ & $5(10.6)$ & $3(8.1)$ \\
\hline B2 & $20(22.2)$ & $20(24.7)$ & $10(21.3)$ & $9(24.3)$ \\
\hline B3 & $14(15.6)$ & $12(14.8)$ & $9(19.1)$ & $8(21.6)$ \\
\hline Thymic carcinoma & $17^{\mathrm{a}}(18.9)$ & $13(16.0)$ & $16^{\mathrm{a}}(34.0)$ & $12(32.4)$ \\
\hline \multicolumn{5}{|c|}{ Masaoka-Koga staging system, n (\%) } \\
\hline \multicolumn{5}{|c|}{ Thymoma } \\
\hline I & $34(46.6)$ & $30(44.1)$ & $10(32.3)$ & $10(40.0)$ \\
\hline II & $21(28.8)$ & $21(30.9)$ & $11(35.5)$ & $6(24.0)$ \\
\hline III & $7(9.6)$ & $6(8.8)$ & $4(12.9)$ & $3(12.0)$ \\
\hline IVA & $8(11.0)$ & $8(11.8)$ & $4(12.9)$ & $4(16.0)$ \\
\hline IVB & $3(4.1)$ & $3(4.4)$ & $2(6.5)$ & $2(8.0)$ \\
\hline \multicolumn{5}{|l|}{ Thymic carcinoma } \\
\hline I & $0(0.0)$ & $0(0.0)$ & $0(0.0)$ & $0(0.0)$ \\
\hline II & $8(47.1)$ & $7(53.8)$ & $8(50.0)$ & $6(50.0)$ \\
\hline III & $6(35.3)$ & $4(30.8)$ & $5(31.3)$ & $3(25.0)$ \\
\hline IVA & $1(5.9)$ & $1(7.7)$ & $1(6.3)$ & $1(8.3)$ \\
\hline IVB & $2(11.8)$ & $1(7.7)$ & $2(12.5)$ & $2(16.7)$ \\
\hline \multicolumn{5}{|c|}{ Treatment before and after operation, n (\%) } \\
\hline \multicolumn{5}{|c|}{ Thymoma } \\
\hline Chemotherapy & $7(9.6)$ & & & \\
\hline Radiotherapy & $0(0.0)$ & & & \\
\hline Chemoradiotherapy & $3(4.1)$ & & & \\
\hline \multicolumn{5}{|l|}{ Thymic carcinoma } \\
\hline Chemotherapy & $3(17.6)$ & & & \\
\hline Radiotherapy & $1(5.9)$ & & & \\
\hline Chemoradiotherapy & $2(11.8)$ & & & \\
\hline
\end{tabular}

a'One case was thymic squamous cell carcinoma combined with type B2 thymoma. IHC, immunohistochemical; RT-qPCR, reverse transcriptionquantitative PCR.

mRNA expression levels had significantly shorter RFS $(\mathrm{P}=0.006$, the Gehan-Breslow-Wilcoxon test) than those with low GAD1 mRNA expression levels (Fig. 3B). Patients with GAD1 protein-overexpressing tumors had significantly shorter RFS ( $\mathrm{P}=0.029$, the Log-rank test) than those without GAD1 protein-overexpressing tumors (Fig. 3C).

\section{Discussion}

We previously performed genome-wide screening on aberrantly methylated CGI in TET and identified 92 CGI that were significantly hypermethylated in $\mathrm{TC}$ relative to B3 thymomas. CGI within the GADI gene were the 4th 
Table II. Association between GAD1 immunoreactivity and clinicopathological factors in 81 patients with thymic epithelial tumors.

GAD1 immunoreactivity

Factor

\begin{tabular}{ccc}
\hline Negative $(n=50)$ & Positive $(n=31)$ & P-value $^{\text {a }}$ \\
$13 / 37$ & $14 / 17$ & 0.075 \\
$60.4 \pm 12.8$ & $57.2 \pm 13.2$ & 0.20 \\
$40 / 10$ & $18 / 13$ & 0.033 \\
$29 / 20 / 1$ & $7 / 12 / 12$ & $<0.001$ \\
$5.51 \pm 5.49$ & $22.63 \pm 20.86$ & 0.011 \\
$0.37 \pm 0.47$ & $2.16 \pm 3.47$ & 0.018 \\
$11 / 39$ & $6 / 25$ & 0.78
\end{tabular}

Sex, male/female

Mean age \pm SD

Masaoka-Koga staging system, stages I and II vs. III and IV

WHO histological classification, A, AB and B1 vs. B2 and B3 vs. carcinoma

Mean GAD1 DNA methylation \pm SD

Mean GAD1 mRNA expression \pm SD

Myasthenia gravis, +/-

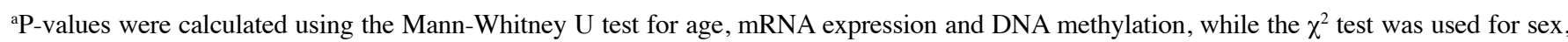
Masaoka-Koga staging system, WHO classification and myasthenia gravis. GAD1, glutamate decarboxylase 1; WHO, World Health Organization.

Table III. Cox proportional hazard regression analysis of relapse-free survival in 90 patients with thymic epithelial tumors.

\begin{tabular}{|c|c|c|c|c|c|c|}
\hline \multirow[b]{2}{*}{ Factor } & \multicolumn{3}{|c|}{ Univariate analysis } & \multicolumn{3}{|c|}{ Multivariate analysis } \\
\hline & Hazard ratio & $95 \% \mathrm{CI}$ & P-value & Hazard ratio & $95 \% \mathrm{CI}$ & P-value \\
\hline Sex [male $(n=31)$ vs. female $(n=59)]$ & 1.083 & $0.423-2.776$ & 0.868 & 0.344 & $0.084-1.416$ & 0.139 \\
\hline Age $[\geq 62(n=45)$ vs. $<62(n=45)$ years $]$ & 0.548 & $0.205-1.466$ & 0.231 & 0.586 & $0.154-2.238$ & 0.435 \\
\hline $\begin{array}{l}\text { Masaoka-Koga staging system } \\
\text { (stages I and II vs. III and IV) }\end{array}$ & 5.532 & $1.941-15.771$ & 0.001 & 5.727 & $1.689-19.423$ & 0.005 \\
\hline $\begin{array}{l}\text { World Health Organization histological } \\
\text { classification (A, AB and B1 vs. B2 } \\
\text { and B3 vs. carcinoma) }\end{array}$ & 3.974 & $1.990-7.938$ & $<0.0001$ & 7.517 & $2.156-26.202$ & 0.002 \\
\hline $\begin{array}{l}\text { Myasthenia gravis } \\
\text { [with }(n=19) \text { vs. without }(n=71)]\end{array}$ & 0.811 & $0.265-2.477$ & 0.713 & 1.407 & $0.332-5.960$ & 0.643 \\
\hline $\begin{array}{l}\text { GADl mRNA expression } \\
{[\geq 0.69(\mathrm{n}=18) \text { vs. }<0.69(\mathrm{n}=19)]}\end{array}$ & 3.216 & $0.977-10.588$ & 0.055 & NA & NA & NA \\
\hline $\begin{array}{l}\text { GADl DNA methylation } \\
{[\geq 5.4(\mathrm{n}=23) \text { vs. }<5.4(\mathrm{n}=24)]}\end{array}$ & 3.424 & $1.082-10.835$ & 0.036 & NA & NA & NA \\
\hline $\begin{array}{l}\text { GADl immunoreactivity } \\
\text { [negative }(\mathrm{n}=50) \text { vs. positive }(\mathrm{n}=31)]\end{array}$ & 2.800 & 0.996-7.870 & 0.051 & 0.213 & $0.034-1.321$ & 0.097 \\
\hline
\end{tabular}

GAD1, glutamate decarboxylase 1; NA, not applicable.

significantly hypermethylated CGI in TC. In the present study, we focused on the DNA methylation of GADI in TET. GAD is crucially involved in the synthesis of GABA, which is the main inhibitory neurotransmitter system. The mammalian nervous system contains two major isoforms of $G A D$, named by their protein sizes of 67 and $65 \mathrm{kDa}$. GAD67 and GAD65 transcripts are encoded by two separate genes, GAD1 and GAD2, located on chromosomes 2q31.1 and 10p11.23, respectively, in humans $(19,20)$. Previous studies reported that reductions in mRNA expression and DNA methylation at the promoter region of GAD1 were related to the development of several neuronal diseases, such as schizophrenia, bipolar disorder, and cerebellar disorders $(33,34)$. GAD1 expression is abundant in the brain but rarely in other tissues, including the thymus. GAD1 has not been studied in the thymus.

We confirmed that the results obtained from genome-wide screening on aberrantly methylated CGI in TET were accurate. These results revealed that the DNA methylation rate of GADl was significantly higher in TC than in the normal thymus (Fig. 1C); however, no relationship was observed for the DNA methylation rate between thymomas and the normal thymus (Fig. 1C). The DNA methylation rate was significantly higher in TC than in thymomas (Fig. 1E). Furthermore, GADI methylation showed high sensitivity and specificity for discriminating between TC and thymomas (AUC=0.976) (Fig. 1F). We confirmed that GAD1 was hypermethylated in TC relative to thymomas and thymic normal tissues. In our previous study, 
we examined the DNA methylation of 4 cancer-related genes (GHSR, GNG4, HOXD9 and SALL3) selected from 92 CGI and revealed that the DNA methylation of 4 genes was significantly higher in TC and showed high AUC for discriminating between TC and thymomas (18). These findings demonstrated that the DNA methylation rate was significantly higher in TC than in thymomas. Recent comprehensive genetic analyses using next-generation sequencing showed that the incidence of somatic mutations was significantly higher in TC than in thymomas (10-14). Furthermore, not only genetic alterations, but also epigenetic alterations in TC significantly differed from those in thymomas. Clinically, TC differs from thymomas. Thymomas are low-grade malignant and indolent tumors with a good prognosis (5-year overall survival rate: approximately 90\%) and a variable population of immature T cells associated with autoimmune diseases. In contrast, TC is an aggressive malignant tumor with a poorer prognosis (5-year overall survival rate: approximately 50\%) without immature T-cell infiltration and autoimmune disease (1-6). Genetic and epigenetic differences between TC and thymomas may contribute to their clinical differences.

We also revealed that GAD1 mRNA expression levels were significantly higher in TC than in thymomas (Fig. 2A and B). To confirm mRNA results, we examined GAD1 protein expression levels in the FFPE materials of thymomas $(n=68)$ and TC $(n=13)$ using IHC. The immunoreactivity of GAD1 was significantly stronger in TC than in thymomas (92.31 vs. 27.94\%) (Table II). Moreover, GAD1 protein expression correlated with mRNA expression (Table 2). The microarray data published in the Oncoming database showed that with the exception of some brain and kidney cancers, GAD1 was up-regulated in the majority of solid tumors, including those in colorectal, lung, and head and neck cancer patients (21). Previous studies reported the overexpression of $G A D 1$ in oral, nasopharyngeal, colorectal, liver, gastric, and lung cancers (21-26). In an IHC study of nasopharyngeal carcinoma $(n=146)$, GAD1 expression correlated with the primary tumor status and advanced American Joint Committee on Cancer (AJCC) stages (23). In primary oral cancer $(n=80), G A D 1$ expression correlated with lymph node metastasis (22). In our previous study, we revealed that GAD1 expression correlated with pleural invasion, vessel invasion, and advanced stages in non-small cell lung cancer (NSCLC) $(n=162)$ (26). In these cancers, GAD1 expression was identified as an indicator of a poor prognosis. In the present study, we demonstrated that patients with high GAD1 mRNA expression levels had significantly shorter RFS than those with low GAD1 mRNA expression levels (Fig. 3B), and also that patients with $G A D 1$ protein-overexpressing tumors had significantly shorter RFS than those without GAD1 protein-overexpressing tumors (Fig. 3C). Furthermore, $G A D 1$ mRNA and protein expression was associated with a poor prognosis in TET as well as in other cancers.

Previous studies suggested that the GAD1/ $\beta$-catenin/matrix metalloproteinase-7 (MMP-7) interaction affects malignant behaviors $(22,35)$. GAD1 expression controls $\beta$-catenin localization to nuclei and activates MMP7. Tumors with high GAD1 expression levels have a greater potential for invasion and metastasis. Previous studies investigated $\beta$-catenin protein expression in thymomas, but not in TC (36-38). In type $\mathrm{A}, \mathrm{B} 1$, and non-invasive type $\mathrm{B} 2$ thymomas, $\beta$-catenin was located in the cytoplasm, in contrast to invasive type B2 and B3 thymomas, in which membranous immunopositivity was observed (36). Takahashi et al reported that the positive rate of MMP-7 was significantly higher in type $\mathrm{C}$ thymomas than in other types of thymomas, and that all TC $(n=9)$ showed positive immunoreactivity for MMP-7 (39). We speculate that the GAD1/ $\beta$-catenin/MMP7 interaction affects malignant behaviors in TC.

The present results also revealed that the DNA methylation rate of $G A D 1$ was significantly higher in TC than in thymomas and the normal thymus (Fig. $1 \mathrm{C}$ and E), and that its mRNA and protein expression levels was significantly higher in TC than in thymomas (Fig. 2B, Table II). Furthermore, a positive association was observed between mRNA expression and DNA methylation levels (Spearman's rank correlation coefficient, $\mathrm{Q}=0.3542, \mathrm{P}=0.0548$ ) (Fig. 2C). These results showed that the DNA methylation of GAD1 positively correlated with its mRNA and protein expression levels, and that a paradoxical relationship exists between promoter DNA methylation and GAD1 expression. This result is applicable to other cancers, such as colon and liver cancers (21). DNA methylation negatively regulates gene expression in the mammalian genome and inversely correlates with transcription. Recent studies reported that the DNA methylation of several genes positively correlated with mRNA expression levels (40-42). Polycomb repressive complex 2 (PRC2) is the only known complex capable of catalyzing H3K27me3 $(43,44)$. CTCF has been shown to block the transcriptional activity of enhancer elements in a methylation-sensitive manner $(45,46)$. In the present study, four CTCF-binding sites were detected in the GAD1 gene (Fig. 1A). The CTCF-3 site contained four $\mathrm{CpG}$ sites, whereas CTCF-1 had no $\mathrm{CpG}$ site and CTCF-2 and CTCF-4 only had one (Fig. 1A). Using electrophoretic mobility shift assays, Yan et al (21) confirmed that the methylation of CTCF-3 inhibited CTCF binding, whereas that of CTCF-1 and CTCF-2 had no effect. When the CpG sites of CTCF-3 are unmethylated, significant DNA-looping interactions between CTCF-3 and CTCF-1, CTCF-2, and CTCF-4 are generated, a PRC2-repressive complex is formed, and GAD1 expression is repressed. However, when the $\mathrm{CpG}$ sites of CTCF-3 are methylated, the DNA-looping interactions of the four CTCF are not generated and a PRC2-repressive complex cannot be formed. $\mathrm{H} 3 \mathrm{~K} 27 \mathrm{me} 3$ levels are markedly reduced at the GAD1 promoter and GAD1 expression is ultimately reactivated. We speculate that the paradoxical relationship (positive correlation) between promoter DNA methylation and GAD1 expression in TET is due to the inhibition of a PRC2-repressive complex by the methylation of CTCF-3.

The present study had some limitations that need to be addressed. We examined the DNA methylation and mRNA of GAD1 using bisulfite pyrosequencing and RT-PCR in 31 and 25 thymomas and 16 and $12 \mathrm{TC}$, respectively. Thymomas are stratified into 5 entities (types $\mathrm{A}, \mathrm{AB}, \mathrm{B} 1, \mathrm{~B} 2$ and B3) based on the morphology of epithelial cells and the lymphocyte-to-epithelial cell ratio. The numbers of thymoma type A, $\mathrm{AB}$ and $\mathrm{B} 1$ cases were lower (5 for type A, 3 for type $\mathrm{AB}$, and 5 for type B1 thymoma) because these tumors are very rare. Although the ratio of lymphocytes to tumor cells was high in $\mathrm{AB}, \mathrm{B} 1$ and B2 thymomas, we were unable to separate tumor cells from lymphocytes prior to DNA extraction. Therefore, 
the presence of lymphocytes in resected $\mathrm{AB}, \mathrm{B} 1$ and $\mathrm{B} 2$ thymomas may have influenced the promoter methylation rate. We examined GAD1 protein expression in 68 thymoma and 13 TC samples using IHC. We detected GAD1 expression in the tumor cells of each thymoma ( 8 type A, 10 type $A B$, and 18 type $\mathrm{B} 1$ thymomas). We also investigated the immunoreactivity of tumor cells and lymphocytes separately. The number of TC is small comparing with the number of thymomas in this study. However, TC is very rare malignant tumor. Thymomas is also a rare tumor. Incidence rates have ranged from 2.2 to 2.6 per million per year. The incidence rates of TC have ranged from 0.3 to 0.6 per million per year. Other report revealed that thymic carcinoma account for approximately $22 \%$ of all TET. We examined GAD1 DNA methylation and expression in 73 thymomas $(81 \%)$ and 17 thymic carcinomas $(19 \%)$. It is very difficult to make the numbers of thymomas and TC equal (47-50). Since some patients died ( 9 out of 90 patients), we were unable to analyze the overall survival curve.

In conclusion, we herein demonstrated that GAD1 was hypermethylated in TC relative to thymomas and normal thymic tissues. Genetic and epigenetic alterations in TC significantly differed from those in thymomas, which may contribute to their clinical differences. We revealed that the mRNA and protein expression levels of GAD1 were significantly higher in TC than in thymomas. Higher expression levels indicated malignant behavior and shorter RFS as well as other cancers. We speculate that the paradoxical relationship between promoter DNA methylation and GAD1 expression in TET is involved in the inhibition of a PRC2-repressive complex by the methylation of CTCF-3.

\section{Acknowledgements}

The abstract was presented at the 2019 World Conference on Lung Cancer Sep 7-10 2019 in Barcelona, Spain, and published as abstract (no. MA20.02) in Journal of Thoracic Oncology Volume 14, ISSUE 10, S330-S331: 2019.

\section{Funding}

No funding was received.

\section{Availability of data and materials}

The datasets used and/or analyzed during the current study are available from the corresponding author on reasonable request.

\section{Authors' contributions}

SS, KKo, MT, KM and BT analyzed and interpreted patient data on DNA methylation using pyrosequencing. SS, YK and $\mathrm{KKa}$ analyzed and interpreted patient data on mRNA expression using RT-PCR. KKo, NK, HTo and MY performed the immunohistochemical staining and interpreted the association between the clinical data and the immunoreactivity. KKo, HTa and AT designed and conducted the present study. KKo and HTa performed the histological examination of thymic epithelial tumors. SS, KKo and AT were major contributors to the writing of the manuscript. SS and KKo confirm the authenticity of all the raw data. All authors have read and approved the final manuscript.

\section{Ethics approval and consent to participate}

The present study was performed in accordance with the principles outlined in the Declaration of Helsinki. Following the approval of all aspects of the present study by the local Ethics Committee (Tokushima University Hospital; Tokushima, Japan; approval no. 2205-4), formal written informed consent for the use of their tissues and the publication of any associated data was obtained from all patients.

\section{Patient consent for publication}

Not applicable.

\section{Competing interests}

All authors declare that they have no competing interests.

\section{References}

1. Kondo K: Therapy for thymic epithelial tumors. Gen Thorac Cardiovasc Surg 62: 468-474, 2014.

2. Shimosato Y, Mukai K and Matsuno Y: Tumors of the mediastinum. In: AFIP Atlas of Tumor Pathology, Series 4. Armed Forces Institute of Pathology, Washington, DC, 2010.

3. Kondo K and Monden Y: Therapy for thymic epithelial tumors: A clinical study of 1,320 patients from Japan. Ann Thorac Surg 76: 878-885, 2003.

4. Ahmad U, Yao X, Detterbeck F, Huang J, Antonicelli A, Filosso PL, Ruffini E, Travis W, Jones DR, Zhan Y, et al: Thymic carcinoma outcomes and prognosis: Results of an international analysis. J Thorac Cardiovasc Surg 149: 95-100, 101.e1-101.e2, 2015.

5. Berghmans T, Durieux V, Holbrechts S, Jungels C, Lafitte JJ, Meert AP, Moretti L, Ocak S, Roelandts M and Girard N: Systemic treatments for thymoma and thymic carcinoma: A systematic review. Lung Cancer 126: 25-31, 2018.

6. Scorsetti M, Leo F, Trama A, D'Angelillo R, Serpico D, Macerelli M, Zucali P, Gatta G and Garassino MC: Thymoma and thymic carcinomas. Crit Rev Oncol Hematol 99: 332-350, 2016.

7. Krishnan M and Ganti AK: The role of targeted therapy in thymic carcinoma. J Oncol Pharm Pract 25: 1712-1718, 2019.

8. Thomas A, Rajan A, Berman A, Tomita Y, Brzezniak C, Lee MJ, Lee S, Ling A, Spittler AJ, Carter CA, et al: Sunitinib in patients with chemotherapy-refractory thymoma and thymic carcinoma: An open-label phase 2 trial. Lancet Oncol 16: 177-186, 2015.

9. Giaccone G, Kim C, Thompson J, McGuire C, Kallakury B, Chahine JJ, Manning M, Mogg R, Blumenschein WM, Tan MT, et al: Pembrolizumab in patients with thymic carcinoma: A single-arm, single-centre, phase 2 study. Lancet Oncol 19: 347-355, 2018.

10. Wang Y, Thomas A, Lau C, Rajan A, Zhu Y, Killian JK, Petrini I, Pham T, Morrow B, Zhong X, et al: Mutations of epigenetic regulatory genes are common in thymic carcinomas. Sci Rep 4: 7336, 2014.

11. Radovich M, Pickering CR, Felau I, Ha G, Zhang H, Jo H, Hoadley KA, Anur P, Zhang J, McLellan M, et al; Cancer Genome Atlas Network: The integrated genomic landscape of thymic epithelial tumors. Cancer Cell 33: 244-258.e10, 2018.

12. Saito M, Fujiwara Y, Asao T, Honda T, Shimada Y, Kanai Y, Tsuta K, Kono K, Watanabe S, Ohe Y, et al: The genomic and epigenomic landscape in thymic carcinoma. Carcinogenesis 38: 1084-1091, 2017.

13. Enkner F, Pichlhöfer B, Zaharie AT, Krunic M, Holper TM, Janik S, Moser B, Schlangen K, Neudert B, Walter K, et al: Molecular profiling of thymoma and thymic carcinoma: Genetic differences and potential novel therapeutic targets. Pathol Oncol Res 23: 551-564, 2017.

14. Petrini I, Meltzer PS, Kim IK, Lucchi M, Park KS, Fontanini G, Gao J, Zucali PA, Calabrese F, Favaretto A, et al: A specific missense mutation in GTF2I occurs at high frequency in thymic epithelial tumors. Nat Genet 46: 844-849, 2014. 
15. Hirose Y, Kondo K, Takizawa H, Nagao T, Nakagawa Y, Fujino H, Toba H, Kenzaki K, Sakiyama S and Tangoku A: Aberrant methylation of tumour-related genes in thymic epithelial tumours. Lung Cancer 64: 155-159, 2009.

16. Mokhtar M, Kondo K, Namura T, Ali AH, Fujita Y, Takai C, Takizawa H, Nakagawa Y, Toba H, Kajiura K, et al: Methylation and expression profiles of MGMT gene in thymic epithelial tumors. Lung Cancer 83: 279-287, 2014.

17. Kajiura K, Takizawa H, Morimoto Y, Masuda K, Tsuboi M, Kishibuchi R, Wusiman N, Sawada T, Kawakita N, Toba H, et al: Frequent silencing of RASSF1A by DNA methylation in thymic neuroendocrine tumours. Lung Cancer 111: 116-123, 2017.

18. Kishibuchi R, Kondo K, Soejima S, Tsuboi M, Kajiura K, Kawakami Y, Kawakita N, Sawada T, Toba H, Yoshida M, et al: DNA methylation of GHSR, GNG4, HOXD9 and SALL3 is a common epigenetic alteration in thymic carcinoma. Int J Oncol 56: 315-326, 2020.

19. Erlander MG and Tobin AJ: The structural and functional heterogeneity of glutamic acid decarboxylase: A review. Neurochem Res 16: 215-226, 1991.

20. Bu DF and Tobin AJ: The exon-intron organization of the genes (GAD1 and GAD2) encoding two human glutamate decarboxylases (GAD67 and GAD65) suggests that they derive from a common ancestral GAD. Genomics 21: 222-228, 1994.

21. Yan H, Tang G, Wang H, Hao L, He T, Sun X, Ting AH, Deng A and Sun S: DNA methylation reactivates GAD1 expression in cancer by preventing CTCF-mediated polycomb repressive complex 2 recruitment. Oncogene 35: 3995-4008, 2016.

22. Kimura R, Kasamatsu A, Koyama T, Fukumoto C, Kouzu Y, Higo M, Endo-Sakamoto Y, Ogawara K, Shiiba M, Tanzawa $\mathrm{H}$, et al: Glutamate acid decarboxylase 1 promotes metastasis of human oral cancer by $\beta$-catenin translocation and MMP7 activation. BMC Cancer: 13: 555, 2013.

23. Lee YY, Chao TB, Sheu MJ, Tian YF, Chen TJ, Lee SW, He HL, Chang IW, Hsing CH, Lin CY, et al: Glutamate decarboxylase 1 overexpression as a poor prognostic factor in patients with nasopharyngeal carcinoma. J Cancer 7: 1716-1723, 2016.

24. Maemura K, Yamauchi H, Hayasaki H, Kanbara K, Tamayama T, Hirata I and Watanabe M: Gamma-amino-butyric acid immunoreactivity in intramucosal colonic tumors. J Gastroentero Hepatol 18: 1089-1094, 2003.

25. Matuszek M, Jesipowicz M and Kleinrok Z: GABA content and GAD activity in gastric cancer. Med Sci Monit 7: 377-381, 2001.

26. Tsuboi M, Kondo K, Masuda K, Tange S, Kajiura K, Kohmoto T, Takizawa $\mathrm{H}$, Imoto I and Tangoku A: Prognostic significance of GAD1 overexpression in patients with resected lung adenocarcinoma. Cancer Med 8: 4189-4199, 2019.

27. Phillips JE and Corces VG: CTCF: Master weaver of the genome. Cell 137: 1194-1211, 2009.

28. Kim TH, Abdullaev ZK, Smith AD, Ching KA, Loukinov DI, Green RD, Zhang MQ, Lobanenkov VV and Ren B: Analysis of the vertebrate insulator protein CTCF-binding sites in the human genome. Cell 128: 1231-1245, 2007.

29. Travis WD, Brambilla E, Burke AP, Marx A and Nicholson AG WHO classification of tumours of the lung, pleura, thymus and heart. In: World Health Organization Classification of Tumours. 4th edition. Bosman FT, Jaffe ES, Lakhani SR and Ohgaki H (eds). IARC Press, Lyon, pp183-243, 2015.

30. Detterbeck FC, Nicholson AG, Kondo K, Van Schil P and Moran C: The Masaoka-Koga stage classification for thymic malignancies: Clarification and definition of terms. J Thorac Oncol 6 (Suppl 3): S1710-S1716, 2011.

31. Suster S and Moran CA: Primary thymic epithelial neoplasms showing combined features of thymoma and thymic carcinoma. A clinicopathologic study of 22 cases. Am J Surg Pathol 20 1469-1480, 1996

32. Weissferdt A and Moran CA: Thymic carcinoma, part 1: A clinicopathologic and immunohistochemical study of 65 cases. Am J Clin Pathol 138: 103-114, 2012.
33. Heckers S, Stone D, Walsh J, Shick J, Koul P and Benes FM Differential hippocampal expression of glutamic acid decarboxylase 65 and 67 messenger RNA in bipolar disorder and schizophrenia. Arch Gen Psychiatry 59: 521-529, 2002.

34. Huang HS and Akbarian S: GAD1 mRNA expression and DNA methylation in prefrontal cortex of subjects with schizophrenia. PLoS One 2: e809, 2007.

35. Li CM, Kim CE, Margolin AA, Guo M, Zhu J, Mason JM, Hensle TW, Murty VV, Grundy PE, Fearon ER, et al: CTNNB1 mutations and overexpression of Wnt/ $\beta$-catenin target genes in WT1-mutant Wilms' tumors. Am J Pathol 165: 1943-1953, 2004.

36. Vodicka P, Krskova L, Odintsov I, Krizova L, Sedlackova E, Schutzner J and Zamecnik J: Expression of molecules of the Wnt pathway and of E-cadherin in the etiopathogenesis of human thymomas. Oncol Lett 19: 2413-2421, 2020.

37. Yoshino I, Kase S, Yano T, Sugio K and Sugimachi K: Expression status of E-cadherin and $\alpha-, \beta$-, and $\gamma$-catenins in thymoma. Ann Thorac Surg 73: 933-937, 2002.

38. Pan CC, Ho DM, Chen WY, Chiang H, Fahn HJ and Wang LS: Expression of E-cadherin and $\alpha$ - and $\beta$-catenins in thymoma. J Pathol 184: 207-211, 1998

39. Takahashi E, Tateyama H, Akatsu H, Fukai I, Yamakawa Y, Fujii Y and Eimoto T: Expression of matrix metalloproteinases 2 and 7 in tumor cells correlates with the World Health Organization classification subtype and clinical stage of thymic epithelial tumors. Hum Pathol 34: 1253-1258, 2003.

40. Gius D, Cui H, Bradbury CM, Cook J, Smart DK, Zhao S, Young L, Brandenburg SA, Hu Y, Bisht KS, et al: Distinct effects on gene expression of chemical and genetic manipulation of the cancer epigenome revealed by a multimodality approach. Cancer Cell 6: 361-371, 2004

41. Lai AY, Fatemi M, Dhasarathy A, Malone C, Sobol SE, Geigerman C, Jaye DL, Mav D, Shah R, Li L, et al: DNA methylation prevents CTCF-mediated silencing of the oncogene BCL6 in B cell lymphomas. J Exp Med 207: 1939-1950, 2010.

42. Renaud S, Loukinov D, Abdullaev Z, Guilleret I, Bosman FT, Lobanenkov V and Benhattar J: Dual role of DNA methylation inside and outside of CTCF-binding regions in the transcriptional regulation of the telomerase hTERT gene. Nucleic Acids Res 35: 1245-1256, 2007.

43. Ha M, Ng DW, Li WH and Chen ZJ: Coordinated histone modifications are associated with gene expression variation within and between species. Genome Res 21: 590-598, 2011

44. Schuettengruber B, Chourrout D, Vervoort M, Leblanc B and Cavalli G: Genome regulation by polycomb and trithorax proteins. Cell 128: 735-745, 2007.

45. Bell AC and Felsenfeld G: Methylation of a CTCF-dependent boundary controls imprinted expression of the Igf 2 gene. Nature 405: 482-485, 2000

46. Hark AT, Schoenherr CJ, Katz DJ, Ingram RS, Levorse JM and Tilghman SM: CTCF mediates methylation-sensitive enhancer-blocking activity at the H19/Igf2 locus. Nature 405: 486-489, 2000

47. de Jong WK, Blaauwgeers JLG, Schaapveld M, Timens W, Klinkenberg TJ and Groen HJ: Thymic epithelial tumours: A population-based study of the incidence, diagnostic procedures and therapy. Eur J Cancer 44: 123-130, 2008.

48. Gadalla SM, Rajan A, Pfeiffer R, Kristinsson SY, Björkholm M, Landgren $\mathrm{O}$ and Giaccone G: A population-based assessment of mortality and morbidity patterns among patients with thymoma. Int J Cancer 128: 2688-2694, 2011.

49. Mariusdottir E, Nikulasson S, Bjornsson J and Gudbjartsson T: Thymic epithelial tumours: A population-based study. APMIS 118: 927-933, 2010.

50. Zhao Y,Zhao H, Hu D, Fan L, Shi J and Fang W: Surgical treatment and prognosis of thymic squamous cell carcinoma: A retrospective analysis of 105 cases. Ann Thorac Surg 96: 1019-1024, 2013.

This work is licensed under a Creative Commons

Attribution-NonCommercial-NoDerivatives 4.0

International (CC BY-NC-ND 4.0) License. 